\title{
Modulation of Experimental Retinal Vasculitis Using Dexamethasone, Cyclosporin A, and Prazosin
}

\author{
M. R. STANFORD, E. ATKINSON, E. KASP and D. C. DUMONDE \\ London
}

\begin{abstract}
Summary
The effects of dexamethasone, cyclosporin A and prazosin were investigated in an animal model of retinal vasculitis. Both dexamethasone and cyclosporin A reduced the clinical and pathological signs of disease when given from the day of disease onset. Prazosin, an $\alpha_{1}$ adrenergic antagonist, was given during the period of disease induction and blocked fluorescein leakage from actively inflamed retinal vessels, but had little effect on the clinical and pathological signs of disease. This study demonstrates the feasibility of using this animal model for therapeutic trials of antiinflammatory agents in retinal vasculitis. The effect of prazosin on reducing vascular leakage from retinal vessels has implications for the treatment of inflammatory macula oedema in human disease.
\end{abstract}

A number of animal models exist that closely resemble the various forms of human uveitis. In these animals, disease is induced by the inoculation of a purified heterologous retinal protein (such as retinal S-antigen) in Freund's complete adjuvant at a site distant from the eye. The nature of the disease produced depends on the species and strain of animal used, the dose of antigen and the adjuvants used with it. ${ }^{1,2}$ In all these models intraocular inflammation appears to be T-cell dependent, though humoral immunity may be involved in the initiation and regulation of disease. ${ }^{3}$ These models have the potential for evaluating therapeutic regimes and for the development of diagnostic tests for use in human disease. However, in the majority of cases therapeutic trials have used agents given during the induction of disease and have examined the subsequent modulating effects. ${ }^{4,5,6,7}$ This approach has been necessary in order to explore the mechanisms involved in induction and also because, in the commonly used albino Lewis rat, disease is of sudden onset and short duration allowing insufficient time for the pharmacological action of the agents used. However, this is not strictly comparable to the treatment of human disease, where agents are given after disease onset.

In the present study we have used a model of retinal vasculitis in the black hooded Lister rat that shows striking similarities to human disease. ${ }^{8}$ This experimental disease may be serially observed using a fundus camera and lasts long enough to allow drugs given from the clinical onset of disease time to act. The presence of a pigmented retinal pigment epithelium in the Lister rat allows effective fluorescein angiography so that the effects of drugs on inflammatory vascular leakage may be observed. We report the effect of the antiinflammatory drugs dexamethasone and cyclosporin $\mathrm{A}$ on the clinical, angiographic

From Department of Immunology, Rayne Institute, UMDS, St Thomas' Campus, London.

Correspondence to: Mr. M. R. Stanford, FRCS, Department of Ophthalmology, King's College Hospital, London SE5.

Presented at the Annual Congress of the Ophthalmological Society of the United Kingdom, April 1987. 
and pathological features of this disease when given from the day of disease onset. We also report the effect of prazosin, an $\alpha_{1}$ adrenergic antagonist, on the modulation of these features when given during the induction phase of disease.

\section{Material and Methods}

Animals: In all experiments male black hooded Lister rats (Bantin and Kingman) weighing 200$250 \mathrm{~g}$ were used. Animals were maintained under similar conditions in a twelve-hour light/dark cycle. Weight matched controls were used in each experiment. Animals were weighed at the beginning and end of each experiment to assess their state of heath.

Inoculation protocol: All animals were inoculated with $50 \mu \mathrm{g}$ of highly purified bovine retinal S-antigen $^{9}$ dissolved in phosphate buffered saline, and emulsified with enriched Freund's complete adjuvant containing $3 \mathrm{mg} / \mathrm{ml} \mathrm{M}$. tuberculosis strain H.37 (Ministry of Agriculture and Fisheries, Weybridge, England). This was given in divided fractions of $0.1 \mathrm{ml}$ per hind footpad.

Table I. Clinical scoring system in experimental retinal vasculitis (per eye)

\begin{tabular}{lc}
\hline \multicolumn{1}{c}{ Clinical feature } & Score \\
\hline Dilated tortuous vessels & 2 \\
Swollen optic disc & 5 \\
Deep retinal infiltration/periphlebitis & 10 \\
Anterior segment disease $(>1+$ cells $)$ & 20 \\
\hline
\end{tabular}

Table II. Histological scoring system in experimental retinal vasculitis (per eye)

\begin{tabular}{ll}
\hline Histological feature & Score \\
\hline Anterior segment disease & 3 \\
Vitreous cells/ & 1 (isolated or mild) \\
retinal vasculitis & 2 (generalised and \\
& 3 moderate) \\
Photoreceptor loss & 1 (ghagocytes in rod \\
& 2 outer segments) \\
& (estruction) \\
& 3 (25 per cent-75 per cent \\
& 4 destruction) \\
& 1 (total destruction) \\
Choroidal disease & 2 (confluent or isolated) \\
& generalised) \\
\hline
\end{tabular}

Clinical observation: Animals were observed from day 10 post-inoculation using a slit lamp biomicroscope and fundus camera. ${ }^{10}$ Disease onset was defined as the appearance of vitreous cells and dilatation and tortuosity of retinal vessels. Disease duration was defined as the time from disease onset until resolution of clinical signs and a reduction in vitreous cells. A system was used to score disease activity on each day of observation (Table I).

Fluorescein angiography: At the end of each experiment animals were anaesthetised with urethane $1.5 \mathrm{~g} / \mathrm{kg}$ and fluorescein angiograms carried out as described elsewhere. ${ }^{10}$ The animals were then killed and freshly enucleated eyes placed in 4 per cent glutaraldehyde (Emscope Laboratories), trimmed and then placed in 10 per cent neutral buffered formalin. Eyes were subsequently dehydrated in graded alcohols, cleared in toluene and wax embedded. Paraffin sections, taken at 100 $\mu \mathrm{m}$ intervals, were stained with haematoxylin and eosin. Histological scoring was performed according to various features listed in Table II.

\section{Experimental Groups}

(1) Dexamethasone study: Eighteen animals were used: nine experimental and nine control. From the day of disease onset a pair of animals was weight matched as nearly as possible and started on treatment: dexamethasone (B.P.) was given daily via intraperitoneal injections (I.P.) at a dose of $4 \mathrm{mg} / \mathrm{kg}$ dissolved in normal saline; control animals received normal saline alone. Treatment was continued for 14 days, and the animals were then killed.

(2) Cyclosporin A: Eighteen animals were used: nine experimental and nine control. Cyclosporin A was a gift of Sandoz Pharmaceuticals, Basel, Switzerland. On the day of disease onset animals received cyclosporin A at a dose of $10 \mathrm{mg} / \mathrm{kg}$ dissolved in commercially available olive oil I.P; control animals received olive oil alone. Treatment was continued for 14 days when the animals were killed. Levels of cyclosporin A were measured in whole blood using the cyclosporin RIA kit according to the manufacturer's instructions (Sandoz Pharmaceuticals).

(3) Prazosin: Chemically pure prazosin was a gift of Pfizer Pharmaceuticals, Sandwich, Kent, and was suspended in normal saline by ultrasonication. Twenty-five animals were used: 16 experimental and nine controls. In this experiment prazosin was given during the induction phase of disease starting on day 7 post-inoculation rather than on the day of disease onset. The drug was given at a dose of 6 $\mathrm{mg}$ /day I.P. and continued for two weeks; control animals received normal saline alone. Animals 
Table III. Comparison of three modes of treatment in experimental retinal vasculitis

\begin{tabular}{|c|c|c|c|c|c|c|}
\hline Drug & $\begin{array}{l}\text { Time of } \\
\text { onset* }\end{array}$ & $\begin{array}{l}\text { Clinical } \\
\text { score }\end{array}$ & $\begin{array}{l}\text { Fluorescein } \\
\text { features }\end{array}$ & $\begin{array}{l}\text { Histological } \\
\text { score }^{*}\end{array}$ & $\begin{array}{l}\text { Weight } \\
\text { change } \\
\text { during } \\
\text { treatment }\end{array}$ & $\begin{array}{l}\text { Duration } \\
\text { of } \\
\text { disease }^{*}\end{array}$ \\
\hline Control $n=9$ & $14.5 \pm 10.6$ & \multirow{3}{*}{$\begin{array}{l}\text { Treated had } \\
\text { lower scores } \\
1 \text { day after } \\
\text { onset } \dagger\end{array}$} & \multirow{3}{*}{$\begin{array}{l}\text { Treated leaked } \\
\text { less than } \\
\text { controls }\end{array}$} & $4.11 \pm 1.5$ & $18 \%$ gain & $10.2 \pm 2.3$ \\
\hline $\begin{array}{l}\text { DEXA- } \\
\text { METHASONE }\end{array}$ & ns & & & $p=0.05$ & & ns \\
\hline Treated $n=9$ & $15.4 \pm 2.1$ & & & $0.78 \pm 0.58$ & $2 \%$ gain & $6.6 \pm 1.2$ \\
\hline Control $n=9$ & $16.2 \pm 2.1$ & \multirow{3}{*}{$\begin{array}{l}\text { Treated had } \\
\text { lower scores } \\
3 \text { days after } \\
\text { onset } \dagger\end{array}$} & \multirow{3}{*}{$\begin{array}{l}\text { No difference } \\
\text { between } \\
\text { treated and } \\
\text { controls }\end{array}$} & $2.13 \pm 0.72$ & $18 \%$ gain & $8.6 \pm 2.6$ \\
\hline CYCLOSPORIN A & ns & & & $\mathrm{p}<0.05$ & & ns \\
\hline Treated $n=9$ & $16.7 \pm 0.85$ & & & $0.38 \pm 0.18$ & $14 \%$ gain & $5.2 \pm 1.9$ \\
\hline Control $n=10$ & $18.5 \pm 1.1$ & \multirow{3}{*}{$\begin{array}{l}\text { No difference } \\
\text { between } \\
\text { treated and } \\
\text { controls }\end{array}$} & All leaked & $9.8 \pm 4.2$ & $13 \%$ gain & \multirow{3}{*}{ N/A } \\
\hline PRAZOSIN & $\mathrm{p}=0.02$ & & & ns & & \\
\hline Treated $n=15$ & $23.1 \pm 1.3$ & & 1/10 leaked & $8.7 \pm 2.3$ & $7 \%$ gain & \\
\hline
\end{tabular}

* All figures are means \pm SEM. $†$ See Figure 1. Statistical significance derived using Student's t-test.

were then observed for the appearance of specific clinical signs (disc oedema, deep retinal infiltrates), at which time they were killed.

\section{Results}

The results in the three groups of animals are summarised in Table III.

Clinical course of disease: There was no significant difference in either day of onset or in duration of disease between the three groups of control animals. In both dexamethasone and cyclosporin A groups disease onset was similar in treated and control animals but the duration of disease was shortened by active treatment (this was not statistically significant). The clinical disease score was reduced by treatment with both of these agents (Fig. 1) once time had elapsed for their pharmacological action (one day for dexamethasone, three days for cyclosporin A). Prazosin delayed disease onset by a week when compared with controls $(p=0.02$; Student's t-test $)$, but there was no significant difference in clinical scores between treated and control animals.

Fluorescein angiography: All animals in the dexamethasone and cyclosporin A groups showed fluorescein leakage from the disc and inflamed vessels; the steroid treated animals having a qualitative reduction in leakage when compared with their controls. Prazosin treated animals had less fluorescein leakage from swollen optic discs than did controls; moreover, 9/10 treated animals did not have leakage from clinically inflamed vessels (periphlebitis) or deep retinal infiltrates (Fig. 2 ), whereas all control animals leaked from these peripheral lesions.

Histopathology: Histopathological features were scored according to Table II. Dexamethasone treated animals had a significant reduction in inflammatory cells in the vitreous and in the degree of perivasculitis and retinal destruction when compared with controls. Cyclosporin A treated animals had less infiltration of the vitreous and retina than did controls, and there was a trend towards a less marked retinal destruction. Prazosin treated animals and their controls had similar inflammatory infiltration and retinal destruction.

\section{Discussion}

In this study we have examined the modulating effect of three pharmacological agents on an animal model of retinal vasculitis. Disease in these animals comes on in the third week post-inoculation and may last up to fourteen 


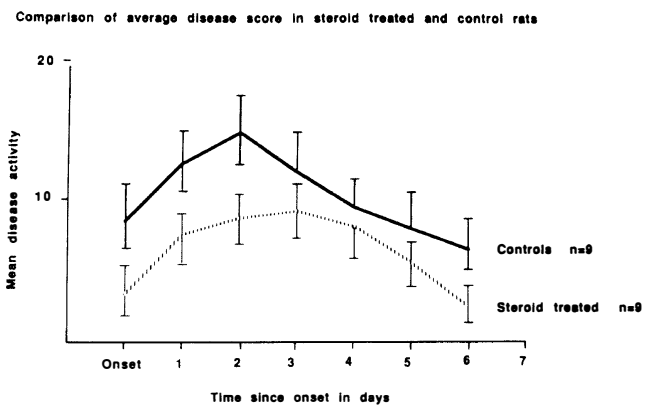

Fig. 1a.

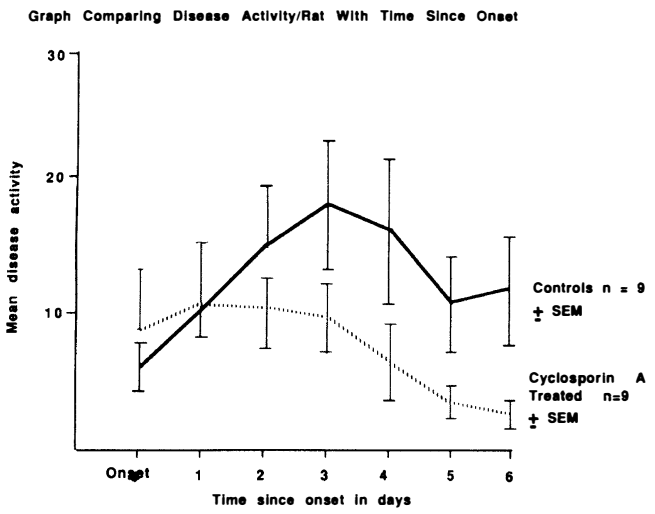

Fig. 1 b.

Fig. 1. A comparison of the clinical scores of treated versus control animals in (a) steroid treated and (b) cyclosporin $A$ treated animals.

days, thus allowing time for these agents to act during the expression rather than the induction of disease. Whilst both dexamethasone and cyclosporin $\mathrm{A}$ have been evaluated in terms of their effects on the induction phase of experimental uveitis in other models,${ }^{4,5,6}$ they have not been extensively investigated during disease expression. ${ }^{11} \mathrm{We}$ also report the effect of prazosin, an $\alpha_{1}$ adrenergic antagonist, on reducing inflammatory vascular leakage in this model.

Steroids are the main drugs used in current clinical practice to control the inflammatory response in human retinal vasculitis. A major action of dexamethasone is to reduce Interleukin- 2 production by resting T-cells and thus to inhibit their proliferative response. ${ }^{12}$ Dexamethasone was shown to reduce the clinical severity and pathological signs of experimental uveitis in both this study and others. ${ }^{5,11}$ However, the relevance of its anti-inflamma- tory action in experimental as compared to human disease is limited as the dose given is huge when translated into human terms, and steroids cause lysis of lymphocytes in rodents, rather than suppression which is seen in man. ${ }^{13}$

Cyclosporin A is of known benefit in reducing those immune responses that are T-cell dependent in both experimental and human autoimmune disease. ${ }^{4.5 .14} \mathrm{It}$ is thought to act at several sites in the T-cell activation process $^{12,15,16}$ and block proliferative responses. In this study cyclosporin A was effective in reducing the clinical and pathological signs of disease, this effect occurring three days after the start of treatment. Adequate levels of drug were achieved in the serum (data not shown) by intraperitoneal injection and there were no untoward effects on the health of animals. Cyclosporin reduced the clinical signs of disease three days after the onset of treatment and this was maintained through the rest of the study. No effect was seen on fluorescein leakage. Pathologically there was a reduction in vitreous infiltration and lymphocytic perivasculitis with a trend towards less marked retinal destruction. Thus cyclosporin A reduced clinical disease but retinal destruction still occurred, suggesting that to be fully effective the drug should be given before the onset of disease, as noted by other authors. ${ }^{5,11}$

Prazosin, a quinazoline derivative, is a specific $\alpha_{1}$ adrenergic antagonist used widely as an anti-hypertensive agent. Its use in this study was prompted by the reports of Brosnan et al. ${ }^{17.18}$ who found that it reduced the clinical signs of experimental allergic encephalomyelitis (EAE) by inhibiting inflammatory vascular leakage as determined by radiolabelled protein studies; this action being attributed to an inhibition of local vasoconstrictive events early in the establishment of delayed-type hypersensitivity (DTH) reactions. It is thought that such events are mediated through the release of vasoactive amines from local mast cells stimulated by $\operatorname{IgE}$ or factors released from activated antigen specific T-lymphocytes; ${ }^{19}$ these mediators increase vascular permeability allowing egress of serum proteins involved in subsequent inflammation. Prazosin-but not $\alpha_{2}$ (yohim- 


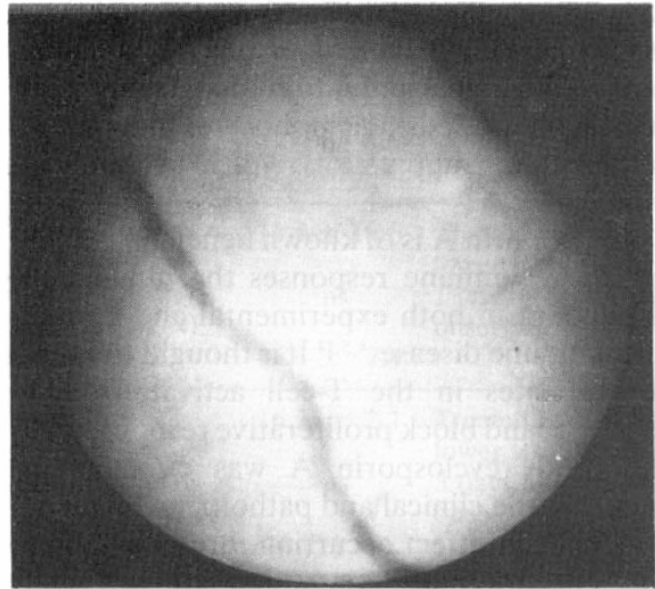

Fig. 2a

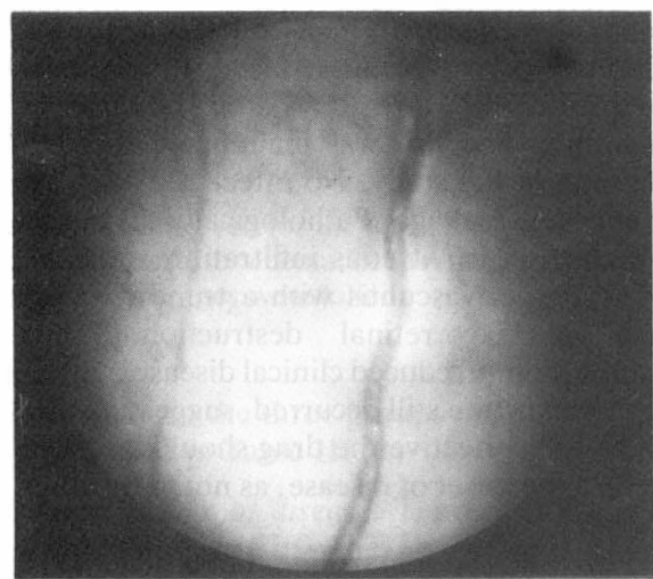

Fig. 2c.

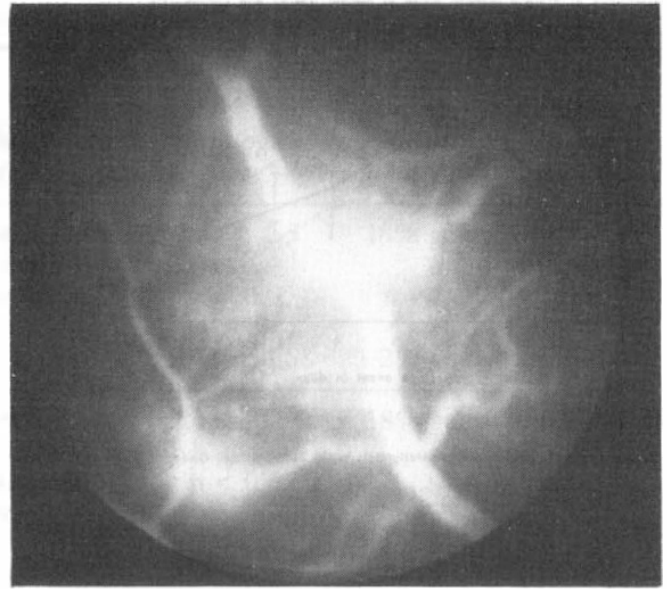

Fig. 2b.

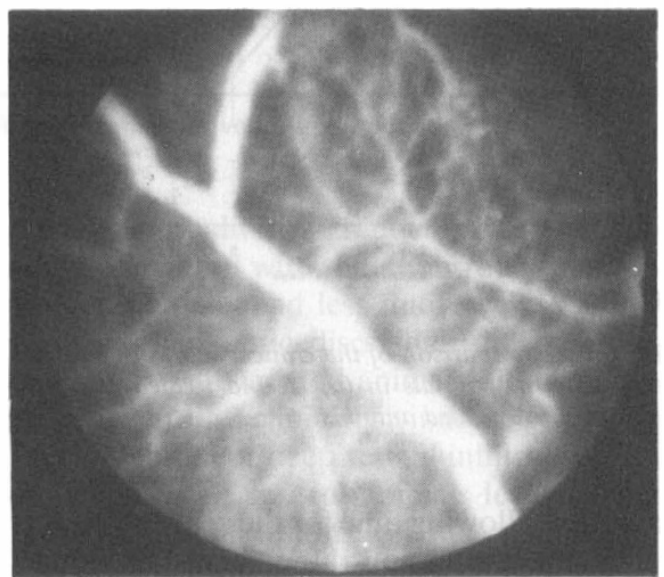

Fig. 2d.

Fig. 2. (a) Black and white fundus photographs, and (b) fluorescein angiograms in the midvenous phase of the retinal periphery of an untreated rat three days after disease onset showing leakage of dye in areas of deep retinal infiltrates. Similar pictures in a prazosin treated rat, at the same stage of disease, show that though there is clinical evidence of retinal infiltration (c), fluorescein leakage does not occur $(d)$.

bine) or $\beta$ (propanolol) adrenergic blockerswas able to suppress increased vascular permeability in EAE. In this study prazosin, given during the induction phase of disease (days 7 to 21), delayed the onset of clinical disease though the clinical score of treated and control animals was not significantly different. However, fluorescein angiography of the treated animals at a similar stage of disease (periphlebitis, deep retinal infiltrates) showed that leakage was markedly reduced from swollen optic discs and abolished around inflamed vessels. No effect was seen histo- logically on lymphocyte infiltration of the retina. The exact site of action of prazosin in this model is not known as retinal vessels are not sympathetically innervated (though the endothelium may contain $\alpha$ adrenergic receptors ${ }^{20}$ nor does the retina contain appreciable numbers of mast cells. ${ }^{21}$

This study has shown that a model of retinal vasculitis in the black hooded Lister rat may be of practical importance in the assessment of anti-inflammatory drugs given from the onset of disease rather than during disease induction; this being the situation encoun- 
tered in clinical practice. Both dexamethasone and cyclosporin $\mathrm{A}$ reduced the clinical signs of disease in addition to attenuating the histological features of retinal inflammation. Prazosin delayed the onset of disease and significantly reduced the fluorescein leakage from inflamed retinal vessels. As leakage of fluid from peripheral retinal vessels in human retinal vasculitis leads to macula oedema-a major cause of visual morbidity in this condition-prazosin may improve the visual prognosis: further studies to investigate this phenomenon are in progress.

The authors wish to thank Mr. R. Dewhirst for assistance with retinal photography and in the preparation of illustrations, Ms. E. C. Brown for technical assistance, and Ms. Sandra DiCarlo for typing the manuscript. This work was made possible by grants from the MRC (grant no 8303319 SB), the T.F.C. Frost Foundation, and the Research (Endowments) Committee, St Thomas' Hospital. MRS is a MRC Training Awards Fellow.

\section{References}

${ }^{1}$ Gery I, Mochizuki M, Nussenblatt RB: Retinal specific antigens and immunopathogenic processes they provoke. In Progress in Retinal Research. Eds. N Osborne and J Chader. Pergamon Press, Oxford. 1986, 75-109.

${ }^{2}$ Faure JP: Autoimmunity and the retina. Curr Top Eye Res 1980, 2: 215-302.

${ }^{3}$ De Kozak Y, Sainte-Landy J, Benevenuste J, et al.: Evidence for immediate hypersensitivity phenomena in experimental autoimmune uveoretinitis. Eur J Immunol 1981, 11: 612-7.

${ }^{4}$ Nussenblatt RB, Rodriguez MM, Wacker WB, et al.: Cyclosporin A: Inhibition of experimental autoimmune uveitis in Lewis rats. J Clin Invest 1981, 67: 1228-31.

${ }^{5}$ Mochizuki M, Nussenblatt RB, Kuwabara T, et al.: Effects of cyclosporine and other immunosuppressive drugs on experimental autoimmune uveoretinitis in rats. Invest Ophth Vis Sci 1984, 26: $226-32$.

${ }^{6}$ Nussenblatt RB, Rodriguez MM, Salinas-Carmona MC, et al.: Modulation of experimental autoimmune uveitis with Cyclosporine A. Arch Ophthalmol 1982, 100: 1146-8.

${ }^{7}$ Nussenblatt RB, Dinning WJ, Fujikawa LS, et al.: Local cyclosporine therapy for experimental autoimmune uveitis in rats. Arch Ophthalmol 1985, 103: 1559-62.

${ }^{8}$ Stanford MR, Graham EM, Kasp E, et al.: Retinal vasculitis: Correlation of animal and human disease. Eye 1987, 1: 111-9.

${ }^{9}$ Kasp E, Banga P, Sanders MD, et al.: A novel approach for the purification of human, porcine and bovine S-antigen utilizing hydrophobic absorption chromatography. In Suppl. Invest Ophth Vis Sci (ARVO abstracts) 1985, 26: 97.

${ }^{10}$ Stanford MR, Brown EC, Kasp E, et al.: Experimental posterior uveitis I: A clinical, angiographic and pathological study. $\mathrm{Br} J$ Ophthalmol (in press).

${ }^{11}$ Striph G, Dojt B, Rabin B, et al.: Retinal S antigeninduced uveitis: the efficacy of cyclosporine and corticosteroids in treatment. Arch Ophthalmol 1986, 104: 114-7.

12 Larsson E-L: Cyclosporin A and dexamethasone suppress $\mathrm{T}$-cell responses by selectively acting at distinct sites in the triggering process. J Immunol 1980, 124: 2828-33.

${ }^{13}$ Claman HN: Corticosteroids and lymphoid cells. $N$ Eng J Med 1972, 287: 388-97.

${ }_{14}$ Nussenblatt RB, Palestine AG, Chann CC: Cyclosporin A therapy in the treatment of intraocular inflammatory disease resistant to systemic corticosteroids and cytotoxic agents. $A m \mathrm{~J}$ Ophthalmol 1983, 96: 275-82.

${ }^{15}$ Dos Reis GA and Shevach EM: Effect of cyclosporin $\mathrm{A}$ on $\mathrm{T}$ cell function in vitro: the mechanism of suppression of T-cell proliferation depends on the nature of the T-cell stimulus as well as the differentiation state of the responding T cell. J Immunol 1982, 129: 2360-6.

${ }^{16}$ Lillehoj HS, Malek TR, Shevach EM: Differential effect of cyclosporin A on the expression of $\mathrm{T}$ and B lymphocyte activation antigens. J Immunol 1984, 133: 244-50.

${ }^{17}$ Brosnan CF, Goldmuntz EA, Cammer W, et al.: Prazosin, an $\alpha_{1}$ adrenergic receptor antagonist, suppresses experimental autoimmune encephalomyelitis in the Lewis rat. Proc Natl Acad Sci 1985, 82: 5915-9.

${ }^{18}$ Goldmuntz EA, Brosnan CF, Norton WT: Prazosin treatment suppresses increased vascular permeability in both acute and passively transferred experimental autoimmune encephalomyelitis in the Lewis rat. J Immunol 1986, 137: 3444-50.

${ }^{19}$ Askenase PW, Rosenstein RW, Petak W: T-cells produce an antigen binding factor with in vivo activity analogous to IgE antibody. $J$ Exp Med 1983, 157: 862 .

${ }^{20}$ Wise CN, Dollery CT, Henkind P: The retinal circulation. Harper and Row. London 1971, p. 85.

${ }^{21}$ Smelser GK and Silver S: The distribution of mast cells in the normal eye. Exp Eye Res 1963, 2: 134-40. 